\title{
Some Physical, Chemical and Biological Contaminants Which are Dangerous to Food Safety
}

\author{
Anil Kumar* \\ School of Biotechnology, Devi Ahilya University, Indore, India \\ *Corresponding Author: Anil Kumar, School of Biotechnology, Devi Ahilya University, Indore, India.
}

Received: August 07, 2019; Published: September 10, 2019

\begin{abstract}
Food borne diseases are much common in humans. Food is considered to be the carrier of many pathogenic bacteria, viruses, parasites etc. Besides, there are chances of contamination of chemical substances in the food. In the present article, a brief discussion has been done on food safety and measures which must be taken for food hygiene.

Keywords: Food Safety; Food Poisoning; Bacteria; Hygiene; Chemical Substances
\end{abstract}

\section{Introduction}

It has been found that humans develop food borne diseases the most. Technically, if there occur two or more cases of similar type of disease after consuming a food, it is called food borne disease outbreak or food poisoning [1]. Food is considered to be the most favorable vector for carrying pathogenic microbes including bacteria, viruses, fungi etc. Therefore, food safety is considered to be of utmost importance. Under food safety, it is important to pay attention to, how to prepare food, way of storing the food, handling etc.

\section{Food safety}

For food safety, precautions are essential in order to avoid health hazards and therefore, food safety generally overlaps with food defense to protect the consumers. Food safety may be divided into two parts- Part A is food safety precautions from industry to market and Part B is from market to consumers. The precautions for food safety from industry to market include hygienic conditions followed in the industry, nature of food additives, proper food labeling, presence of pesticide residues, regulations/guidelines from the government for inspection of food consignments for import or export, government certification policies etc. The precautions from market to consumers include safe storage, preparation of food if required and safe delivery to the consumers.

\section{Food contamination}

When food safety is taken into account, people talk of pathogenic microbes. Foods being enriched in nutrients are generally prone to pathogenic microbial infection and thereafter, through food, these microbes are transferred to the people or other animals. Depending upon the microbe, person may become sick or even sometimes death may occur. Foods being enriched in nutrients are one of the best media for the growth and multiplication of the microbes. For preparation of foods, water is considered to be almost essential component. In many countries, especially in poor and developing countries, water has been found to be generally contaminated with microbes or other toxic substances [2]. There is involvement of so many persons in food supply chain, therefore, in spite of taking precautions, it is likely to get the food contaminated with pathogens.

Food hygiene

According to WHO, following precautions are essential for food hygiene [3]:

1. Raw food may have contamination of pathogens, therefore, cooked food must be handled away from the raw food.

2. Food must be cooked at a temperature and for a particular time to destroy live pathogens, if any present in raw material.

Citation: Anil Kumar. "Some Physical, Chemical and Biological Contaminants Which are Dangerous to Food Safety". Acta Scientific Nutritional Health 3.10 (2019): 48-50. 
3. Cooked food as well as raw food must be stored at a temperature so that there must be least chances of getting contamination by pathogens and their multiplication.

4. Clean water and raw material devoid of any pathogenic contamination must be used for cooking the food.

5. Precautions must be taken so that food during or after cooking as well as raw material must not get contaminated with pathogens from the person(s) handling them, pets and pests.

\section{Factors affecting the food safety}

It is considered that food safety becomes at stake due to any one or more following biological, chemical or physical factors:

\section{Biological factors}

Food mostly gets contaminated with pathogenic bacteria. Some most common pathogens contaminating the food are Staphylococcus aureus, Salmonella typhimurium, Clostridium perfringens, Campylobacter etc [4]. It has been found that if food is enriched in starch or protein, moisture and $\mathrm{pH}$ is near neutrality, there are chances of survival of bacteria even on storage in the refrigerator $[5,6]$. It has been found that temperature between $40^{\circ} \mathrm{F}$ (nearly $5^{\circ} \mathrm{C}$ ) to $140^{\circ} \mathrm{F}$ (nearly $60^{\circ} \mathrm{C}$ ) is considered to be the 'danger zone' for food since many bacteria survive and multiply in this temperature range. Besides, there are chances of contamination by viruses and/or parasites. The chances of viral/ parasite contamination may be through saliva, pests, faecal matter etc [7].

Salmonella contamination in the food is very common. It has been found that mostly people get it in their body by eating uncooked or partially cooked poultry items like eggs and meat, raw fruits without proper decontamination, sprouts, milk and other dairy products. This bacteria is also transmitted through contact with infected animals/ food handlers who do not properly clean their hands after using the wash room. It is considered that Salmonella is the main cause of diarrhea, other food borne diseases and sometimes even deaths. The pregnant ladies, older people having comparatively weaker immune system, younger kids are more prone to Salmonella infection. This bacteria if ingested with food is able to survive in the intestine and can spread there. Therefore, it is essential to take care of hygiene and only properly cooked food is eaten. One must wash raw fruits and vegetables using clean water before peeling, cutting and eating. Milk without proper pasteurization must not be consumed. Personal hygiene like cleaning hands at intervals especially after using wash room and before eating something is much important. Cooking areas/kitchen must be in hygienic conditions in order to avoid cross- contamination [4].

Another dreaded bacteria is Clostridium which secretes toxin in the body and causes abdominal cramping and diarrhea. It is also called as 'buffet germ' since it multiplies much faster in gravies, stews etc if stored at a temperature between $40^{\circ} \mathrm{F}$ to $140^{\circ} \mathrm{F}$. Therefore, it is recommended to properly cook the food initially in order to kill the bacteria if any, stored at the appropriate temperature preferably below $40^{\circ} \mathrm{F}$ and food must be again heated at a temperature of $165^{\circ} \mathrm{F}$ (nearly $75^{\circ} \mathrm{C}$ ) or above before consuming it otherwise there are fair chances of consuming live bacteria resulting in severe diseases. Like Salmonella infection, youngsters, older people are more prone to Clostridium infection.

If we talk of Staphylococcus aureus, normally it remains on the skin, nostrils of the humans and other animals and is not harmful to skin. However, if it goes inside the body (alimentary canal) with food or otherwise, it multiplies and secretes toxins there resulting in diarrhea, vomiting, cramps in stomach, nausea etc. If food is contaminated with Staphylococcus aureus, and has multiplied and secreted toxins, being heat resistant, the same can't be destroyed by heating or cooking the food. It has been observed that generally people having lung disease, cancer, diabetes etc are more prone to Staphylococcus aureus infection compared to healthy persons. Generally, this bacteria flourishes on unpasteurized milk and other dairy products like cream filled pastries, cakes, sandwiches and these being part of human food are the source of this bacterial infection. Foods like salads which come in contact of bare hands and are eaten without cooking are also source of Staphylococcus in the digestive system. Therefore, it is recommended that before eating or cooking food, hands must be thoroughly cleaned using soap and clean water. Person having eye/nose/ skin infections or wounds must not cook the food. Cooking as well as food storage areas must be clean and food must be stored at appropriate temperature (out of the danger zone range).

Similarly, a few strains of Escherichia coli may also cause food poisoning, therefore, the same precautions must be taken as mentioned above for Streptococcus and Clostridium. One must not drink or swallow water of the ponds, lakes etc while swimming or otherwise. 
There is another important harmful bacteria, Listeria monocytogenes, which causes listeriosis, a dreaded disease. The people like older persons, pregnant ladies, young infants are more prone to food poisoning due to Listeria monocytogenes. This bacteria can survive at a temperature of the refrigerator, therefore is found in refrigerated foods [4].

\section{Chemical factors}

Many times, food gets contaminated with a chemical substance like chemical pesticides, herbicides, toxins, food additives and other adulterants. Raw vegetables remain contaminated with certain chemicals which are used to prevent pests, herbs etc and if these vegetables are not washed thoroughly with clean water, then there are chances of contamination with these chemical substances $[8,9]$. Sometimes, water used in cooking food itself remains contaminated with certain chemicals which will become part of the food. However, it is considered that normally chemical substances are not added in the food intentionally. Of course, this statement can't be considered to be $100 \%$ true since now a days, there are reports that many chemicals are intentionally used to increase the yield or for better morphological appearance. It is very common especially in poor and developing countries to use chemicals for ripening of fruits. Besides, chemicals exhibit toxic effect when consumed in larger quantity [9].

\section{Physical factors}

Sometimes, food gets contaminated by the objects like hair, plastic piece, small metal piece, plant stalk, glass piece, soil dust, fingernails etc [10]. Although in bigger restaurants, care is taken to avoid contamination by these physical objects by using head cap, gloves up to forearm etc.

\section{Regulations for food safety}

Almost all the countries have strict rules and regulations on food safety in order to protect their people from food poisoning and other food borne diseases which may lead even to deaths. In 1963, World Health Organization (WHO) and Food and Agriculture Organization (FAO) published the food code called as Codex Alimentarius which served as guidelines in framing rules and regulations by various countries.

\section{Conclusion}

Considering the human health which remains in danger due to food contamination, utmost care must be taken for food safety and to avoid food contamination from various sources.

\section{Acknowledgements}

Author acknowledges the facilities of the Department of Biotechnology, Ministry of Science and Technology, Government of India, New Delhi (DBT) under the Bioinformatics Sub Centre as well as M.Sc. Biotechnology program used in the present work.

\section{Bibliography}

1. Texas Food Establishment Rules. Texas DSHS website: Texas Department of State Health Services (2015): 6.

2. Pandey PK., et al. "Contamination of water resources by pathogenic bacteria”. AMB Express 4 (2014): 51.

3. https://en.wikipedia.org/wiki/Food_safety

4. https://www.eatright.org/homefoodsafety/safety-tips/foodpoisoning/most-common-foodborne-pathogens

5. https://www.fsis.usda.gov/wps/portal/fsis/topics/foodsafety-education/get-answers/food-safety-fact-sheets/safefood-handling/danger-zone-40-f-140-f/ct_index

6. https://www.foodsafety.com.au/resources/articles/foodsafety-and-the-different-types-of-food-contamination

7. https://www.foodsafety.com.au/faq/what-are-the-differenttypes-of-food-contamination

8. https://www.foodsafetymagazine.com/magazine-archive1/ februarymarch-2013/modern-analysis-of-chemical-contaminants-in-food/

9. https://www.sciencedirect.com/topics/food-science/chemical-contamination-of-food

10. https://www.campdenbri.co.uk/services/physical-contaminants.php

\section{Volume 3 Issue 10 October 2019 (C) All rights are reserved by Anil Kumar.}

